\title{
A AGENDA DA REFORMA DOS BENEFÍCIOS TRIBUTÁRIOS DAS FAMÍLIAS E DAS EMPRESAS COM SAÚDE: ENTRE O PARTICULAR E O GERAL ${ }^{1}$
}

\author{
Maria de Fátima Siliansky de Andreazzi \\ Ivani Bursztyn \\ Tássia Holguin
}

\author{
Bernardo Sicsú \\ Luiz Fernando Rangel Tura
}

\begin{abstract}
RESUMO
O artigo objetiva analisar a relação do benefício fiscal à saúde do Imposto de Renda (Pessoa Física e Jurídica) com a demanda privada de saúde. Procuramos identificar embates e acordos em torno do tema, em especial, propostas de mudanças no marco regulatório. Para fazer isso, efetuamos estudos documentais e entrevistas semi-estruturadas com representantes de organizações nacionais de sujeitos sociais relevantes ao tema. Verificamos que o debate alcançou arenas importantes de definição das políticas de saúde, mas propostas de mudança não lograram viabilizar-se. As entrevistas sugerem uma convergência com estudos econométricos internacionais sobre a inelasticidade da demanda para atenção à saúde acentuadamente para as famílias, e menos para as empresas. Isso sugere que a questão deve estar inserida num contexto mais geral em relação à equidade no financiamento, não se atendo isoladamente no ponto específico da eliminação do referido subsidio que aumentaria a participação da saúde no orçamento familiar e, também, a carga tributaria das familias, sem que houvesse, automaticamente, uma alocação compensatória de mais recursos públicos para o setor.
\end{abstract}

PALAVRAS-CHAVE: gastos tributários; gastos privados em saúde; relações público-privadas em saúde; economia política da saúde; políticas de saúde no Brasil.

\section{INTRODUÇÃO}

Gastos ou benefícios tributários são gastos públicos indiretos realizados por intermédio do sistema tributário, visando atender a objetivos econômicos e sociais. No Brasil, a Secretaria de Re-

ceita Federal tem considerado, desde 1986, como sendo beneficio tributário toda desoneração que cumulativamente satisfaça os seguintes requisitos: 1) reduza a arrecadação potencial; 2) aumente a disponibilidade econômica do contribuinte; 3 ) constitua, sob o aspecto jurídico, uma exceção à norma que faz referência ao tributo ou alcance, exclusivamente, determinado grupo de contribuintes (SALVI, DE PAULA \& LOURES, 2003). Enquadram-se nesse conceito os abatimentos com gastos de saúde, no Imposto de Renda das Pessoas Físicas (IRPF) e Jurídicas (IRFJ).

Este trabalho faz parte de uma pesquisa ${ }^{2}$ que teve por objetivos (1) avaliar a importância dos benefícios fiscais concedidos pela Secretaria da Receita Federal para assistência à saúde, via de-

\footnotetext{
2 Agradecemos ao Conselho Nacional de Desenvolvimento Científico e Tecnológico (CNPq) e ao Ministério da Saúde pelo apoio financeiro concedido.
} 
dução do Imposto de Renda - Pessoa Física e Jurídica, para a demanda de seguros e serviços privados de saúde; (2) quantificar esses benefícios e (3) identificar os principais sujeitos sociais que têm incluído essa questão na agenda setorial do financiamento da assistência à saúde, no Brasil. Com esses objetivos em mente, apresenta-se os resultados dos estudos documentais e das entrevistas efetuadas com atores políticos julgados relevantes. Procura-se identificar embates e acordos em torno do tema e em face de propostas de mudanças no marco regulatório.

Gastos tributários podem ser substituídos por gastos orçamentários diretos (BEGHIN, 2005). O valor da renúncia de arrecadação fiscal está em função dos gastos que os contribuintes declaram ter com determinados itens de seus dispêndios globais em saúde. No Brasil, esses itens têm variado ao longo do tempo. Deduções de despesas com assistência ambulatorial e hospitalar pagas diretamente aos prestadores de serviços existiam anteriormente à Constituição de 1988. Em 1990, foram estabelecidos tetos a serem aplicados na renda bruta dos contribuintes (referentes ao ano de 1989), que limitavam essas deduções às pessoas físicas (ALMEIDA, 1998). As deduções voltaram a vigorar sem qualquer limite em 1991 (ano base de 1990), tanto para a dedução da renda tributável das pessoas físicas quanto para o lucro tributável das pessoas jurídicas. Vale ressaltar que esse evento refere-se, especificamente, às declarações do tipo "completas", e que os gastos das famílias com medicamentos não foram contemplados, sendo incluídas, apesar disso, as despesas com seguros de saúde. Desde então, não existem limites para a dedução desses gastos da renda tributável (SAYD, 2003). Hoje, esse procedimento está regulamentado pela RIR (Regulamento do Imposto de Renda), de março de 1999. Esse incentivo governamental permitiu que os gastos privados com serviços de atenção à saúde fossem deduzidos da renda tributável das pessoas físicas e do lucro tributável das pessoas jurídicas, reduzindo, dessa forma, o valor do imposto a recolher.

Segundo estimativa da Secretaria da Receita Federal (Coordenação Geral de Política Tributária-Copat), o valor da renúncia de arrecadação fiscal relativa às despesas com planos de saúde e aos desembolsos diretos com a assistência médico-hospitalar foi de $\mathrm{R} \$ 2,8$ bilhões em 2005, sen- do $\mathrm{R} \$ 2,06$ bilhões referentes às pessoas físicas e $\mathrm{R} \$ 770$ milhões às pessoas jurídicas.

Para efeito de comparação dos benefícios tributários em saúde em relação aos gastos públicos em saúde, tomamos o trabalho de Ugá e Santos (2005). As autoras estimaram o gasto público total em saúde, em 2002, em R $\$ 50,5$ bilhões ( $\mathrm{R} \$$ 67,39 bilhões a preços de 2005 , corrigidos pelo IPCA-IBGE ${ }^{3}$ ). A estimativa da magnitude do benefício tributário vis-à-vis o gasto público estaria na ordem de $4,2 \%$. Vale registrar que a despesa total das famílias com atenção à saúde registrada na Pesquisa de Orçamentos Familiares (POF) do IBGE de 2003 foi de R $\$ 23,3$ bilhões. Considerando-se apenas os gastos com seguros e planos de saúde e atenção médico-hospitalar, itens que permitem dedução no $\mathrm{IRPF}^{4}$, os valores são de R $\$ 13$ bilhões correntes, que correspondem, em 2005 , a R $\$ 14,79$ bilhões (valores corrigidos pelo IPCA-IBGE). Cabe ressaltar que, em 2005, o consumo das famílias com "planos de saúde" foi da ordem de R \$ 8,632 milhões (IBGE, 2008). O benefício representaria, portanto, em torno de $13,9 \%$ do gasto das famílias com aqueles itens, referentes à saúde. Para o ano de 1999, Sayd (2003) estimou em R \$ 1,014 bilhão os benefícios tributários em saúde do IRPF, representando 11,39\% sobre as deduções com despesas em saúde.

Cabe lembrar que, para as pessoas físicas, há opções de declaração em que os gastos e, conseqüentemente, os benefícios tributários com a saúde, não são individualizados, como as declarações no formulário do tipo "simplificado", gerando o denominado "desconto-padrão", e a declaração dos contribuintes situados na categoria de "isentos". $\mathrm{O}$ percentual de declarações que se enquadram nessas categorias é estimado por técnicos da Receita Federal como sendo em torno de $34,5 \%$ do total, para o ano de $2004^{5}$. Para as pessoas jurídicas ocorre situação similar, quanto às declarações simplificadas.

\footnotetext{
3 Instituto de Preços ao Consumidor Amplo, Instituto Brasileiro de Geografia e Estatística.

4 A diferença é, sobretudo, devida aos gastos das famílias com medicamentos, item em que os abatimentos no imposto de renda não são permitidos.

5 Dado obtido junto a técnico da Secretaria da Receita Federal.
} 
O montante do benefício aumenta com a renda da família, sendo que, na faixa da alíquota de $15 \%$, que representavam, em 1999, uma renda entre R\$ 1080 e R\$ 2160 (aproximadamente de 3 a 6 salários mínimos da época), a dedução média foi de R\$152. Para a faixa de renda acima de R\$ 2160 (6 salários mínimos), a dedução média foi de R\$ 771 (SAYD, 2003). O gasto privado em saúde apresentado na POF de 2003 acompanha esse padrão. No caso das pessoas jurídicas, o beneficio tributário, em 2003 (último ano disponível), representou $15 \%$ das deduções.

As tendências do benefício tributário, visualizadas entre 1998 e 2005, são de recuperação, em 2005, em relação ao período anterior, para as pessoas físicas, e de queda, para as jurídicas. Isso acompanha a queda da renda das famílias entre as POFs, de 1998 e 2003.

Estudos econométricos (GRUBER, 2001), realizados principalmente no âmbito norte-americano e europeu, que modelaram os impactos da redução dos benefícios fiscais sobre a demanda por planos privados de saúde, apontaram para uma maior sensibilidade das firmas empregadoras do que das pessoas físicas no que se refere à redução das pessoas com cobertura de planos, dada a redução do beneficio tributário. Os autores que trabalham com essa metodologia admitem que, para as famílias, os gastos em saúde seriam relativamente inelásticos aos preços desses bens e serviços.

Sendo assim, as hipóteses de trabalho são as seguintes.

1) A retirada do subsídio implicaria numa redução da capacidade de compra de bens e serviços de saúde por parte das famílias, particularmente aquelas situadas acima do limite de isenção do IRPF. Para as famílias com renda acima de trinta salários mínimos o impacto seria menos significativo, pois, de acordo com Sayd (2003), a participação do benefício tributário em sua renda declarada era inferior àquela encontrada nas famílias de renda na faixa de 6 a trinta salários mínimos. Isso também pode ser observado na POF de 2003, ou seja, a participação percentual dos gastos em saúde na renda das famílias é menor naquelas de renda mais elevada.

2) O mesmo deve ocorrer com as empresas, especialmente aquelas com atuação em mercados competitivos, em que a capacidade de de- terminação de preços é incontrolável, sendo, portanto, mais sensíveis a aumentos de custo com sua força de trabalho.

3) O recorte ortodoxo das políticas econômicas dos governos que se sucederam nos anos 1990 e 2000 não nos autoriza a inferir o estabelecimento de cenários expansivos do gasto público em saúde que, por sua vez, absorvam parte de uma demanda que, atualmente, recorreria ao setor privado caso houvesse a redução e a extinção desse benefício; demanda esta constituída, principalmente, por famílias de renda mais baixa.

4) A retirada do beneficio implicaria em menos informações sobre a base de faturamento dos prestadores privados de serviços de saúde, para finalidades fiscais.

\section{METODOLOGIA}

O primeiro objetivo de nossa pesquisa é a identificação dos atores políticos relevantes envolvidos na questão, o que envolveria conflitos clássicos de distribuição de recompensas e sanções sociais (ALEXANDER, 1998). Dois métodos, complementares, foram adotados para essa identificação: um, dedutivo, foca o estabelecimento das possíveis relações dos benefícios tributários face às políticas de reprodução social do Estado brasileiro, a partir dos anos 1990, identificando grupos sociais, ganhadores ou perdedores, partindo da hipótese de existirem alterações nessa política tributária; o outro, indutivo, consiste numa pesquisa documental sobre o tema.

Benefícios tributários não se coadunam com a ortodoxia econômica neoliberal adotada no período. Subsídios fiscais distorceriam a competição econômica no mercado, contribuindo para uma ineficiente alocação dos recursos na atenção à saúde (DOWD et alii, 2001). Seria previsível que a área econômica do governo fosse contrária a eles. Ponderações de ordem fiscal poderiam contrapor-se aos argumentos doutrinários, em prol manutenção desses benefícios. Assim como ponderações de ordem política, na busca de apoio das camadas médias e do empresariado, na falta de alternativas que compensassem a sua perda.

Parcela importante da reparação da força de trabalho formal no Brasil, nesse período, tem sido de responsabilidade compartilhada entre as empresas e os trabalhadores, por meio da cobertura privada de saúde. O mesmo tem ocorrido com 
famílias de renda média e alta, inseridas ou não em mercados formais de trabalho. Para ambas, o beneficio tributário poderia ter algum papel na manutenção do perfil de consumo dos serviços de saúde.

Com isso, chegou-se ao quadro apresentado a seguir:

QUADRO 1 - CONFLITOS DISTRIBUTIVOS POTENCIAIS EM TORNO DO PROBLEMA DA PERDA OU
REDUÇÃO DOS BENEFICIOS TRIBUTÁRIOS PARAPESSOAS FÍSICAS E JURIDICAS COM
GASTOS PRIVADOS DE SAÚDE NO BRASIL

FONTE: Elaboração dos autores.

A pesquisa documental foi efetuada por meio da internet e em bases de dados acadêmicas (como o Scielo), utilizando identificadores das palavraschave "renúncia fiscal", "benefícios tributários", "saúde" e "Brasil", com a ajuda de ferramentas específicas (como o Google).

Além disso, utilizando autores que analisaram as políticas de saúde no Brasil (BRAVO 2001; MONTONE, 2004), considerou-se a existência de alguns espaços importantes de formulação e decisão, como o Conselho Nacional de Saúde e a Câmara de Saúde Suplementar, órgão consultivo da Agência Nacional de Saúde Suplementar, em que estavam presentes alguns representantes de movimentos sociais

Também não se poderia deixar de levar em conta a dimensão legislativa da mudança, o que remeteria a uma investigação empírica no espaço do Congresso Nacional. O levantamento foi efetuado entre os meses de junho de 2005 e outubro de 2006. Os resultados iniciais pouco contribuíram para a identificação de atores específicos: à parte de alguns órgãos do Governo Federal e de parcela da comunidade acadêmica da área de Saúde Coletiva, o tema não teve maior visibilidade nos espaços investigados.

Para o planejamento do trabalho de campo, apoiamo-nos, principalmente, no esquema dedutivo já mencionado. A unidade de análise adotada foram as organizações representativas dos grupos sociais, procurando identificar as ações empreendidas quanto ao tema, assim como seu possível posicionamento face às mudanças. Foram construídas amostras de conveniência de cada grupo, tendo como critério a sua representatividade diante do conjunto. Foram entrevistados presidentes e dirigentes dessas organizações, em que, além das perguntas objetivas, voltadas às ações empreendidas pelo grupo, buscou-se investigar suas opiniões quanto ao papel da renúncia fiscal nos padrões de demanda e de gasto privado em saúde dos indivíduos entrevistados e quanto às bases das respectivas organizações.

As entrevistas, semi-estruturadas, foram realizadas no período de junho de 2005 a outubro de 
2006. Foi utilizado um roteiro, com perguntas abertas, que possuía uma parte comum e uma específica, para cada grupo de informantes. As respostas foram anotadas pelo pesquisador e revisadas pelo entrevistado. Duas entrevistas foram gravadas, transcritas e revisadas pelos entrevistados.

Foram entrevistados, ao todo, quatorze indivíduos. Esses entrevistas foram realizadas no Rio de Janeiro, São Paulo, Fortaleza, Brasília, Belo Horizonte e Florianópolis, buscando abranger várias regiões do país. Cinco organizações que inicialmente estavam listadas recusaram-se a participar, mas foram repostas dentro do mesmo grupo de atores. A alocação da organização entrevistada ao grupo social de interesse é apresentada no Quadro 2.

QUADRO 2-DESCRIÇÃO DAAMOSTRA

\begin{tabular}{|c|c|}
\hline Composição da amostra & $f$ \\
\hline $\begin{array}{l}\text { Governo Federal } \\
\text { - Área da Saúde }\end{array}$ & 3 \\
\hline $\begin{array}{l}\text { Famillas de renda média e média aita } \\
\text { - Representaçẫo de advogados e } \\
\text { associaçốes de defesa do consumidor }\end{array}$ & 2 \\
\hline $\begin{array}{l}\text { Familias de renda média baixa } \\
\text { - Representaçẫo de taxistas }\end{array}$ & 1 \\
\hline $\begin{array}{l}\text { Emoresas } \\
\text { - Representaçẫo de transporte rodowiário e } \\
\text { de escolas }\end{array}$ & 2 \\
\hline $\begin{array}{l}\text { Prestadores de servços privados } \\
\text { - Representaçóes de médicos, prestadores } \\
\text { de serviços de saúde, seguros e planos } \\
\text { privados de saúde }\end{array}$ & 5 \\
\hline $\begin{array}{l}\text { Operariado } \\
\text { - Representaçẫo de trabalhadores em } \\
\text { transporte rodoviário }\end{array}$ & 1 \\
\hline Total & 14 \\
\hline
\end{tabular}

FONTE: Elaboração dos autores.

Embora a quantidade de depoimentos seja pequena, foi avaliado que as entidades representativas obedeciam a um critério importante para a pesquisa qualitativa, que é a tipicidade dos casos estudados em relação ao conjunto (COAST, MCDONALD \& BAKER, 2004). Assim, quatro das cinco organizações de prestadores de serviços de saúde tinham representatividade nacional e, a outra, estadual. Por parte dos empresários, considera-se representações estaduais e municipais de categorias típicas de pequenos empresários, por um lado, e de médios e grandes, por ou- tro. Das famílias, representações de defesa do consumidor de âmbito nacional. No que se refere às demais, considera-se categorias em que a relação de trabalho autônoma é importante, além de entidades de nível estadual.

Quanto ao Estado, um dos entrevistados encontrava-se na mais alta hierarquia de seu respectivo órgão e, os demais, em níveis intermediários de direção, diretamente relacionados com temas de financiamento. Espera-se, com a análise qualitativa, identificar os temas centrais relacionados ao problema de estudo. Assim, o que importou foi a qualidade do insight gerado - seu poder explicativo (PATTON, 2002). Procedeu-se a uma seleção adequada de informantes-chave - pessoas que pudessem ter aportes importantes ao tema -, adotando-se técnicas apuradas para colher o máximo de informação em cada entrevista (SOBO, 2009). A análise qualitativa difere, portanto, da proposta de estudos descritivos, em que o tamanho e a representatividade da amostra são fatores determinantes no desenho da investigação. Realizou-se uma análise de conteúdo do material dos documentos e das entrevistas, procurando identificar as categorias do discurso dos diferentes atores. Os resultados são apresentados nos agregados, e segmentados por grupos de informantes.

\section{RESULTADOS}

\section{III.1. Pesquisa Documental}

As referências mais antigas a respeito do tema da renúncia fiscal em saúde, por meio dos benefícios tributários associados ao IRPF e ao IRPJ, foram encontradas na literatura da área de Saúde Coletiva (ANDREAZZI, 1991; MÉDICI, 1992). Esses trabalhos procuraram identificar o problema e quantificá-lo a partir das fontes disponíveis, chamando a atenção para um de seus papéis: o de subsídio voltado à atenção privada. Apontaram, ainda, as possíveis relações com a manutenção de um padrão de oferta privada de importante magnitude no Brasil, além do crescimento do mercado de seguros de saúde privados (OCKE-REIS, 1995). A partir dos anos 1990, encontram-se reflexões sobre o tema em Dain (2000), Sayd (2003) e Ugá e Santos (2005). Estas últimas sintetizam o posicionamento dos trabalhos mais recentes que criticam a visão daqueles que consideram a renúncia fiscal com abatimentos regressivos do Imposto de Renda como um modelo de financiamento para a saúde: grosso modo, esse modelo favoreceria mais os grupos com maior capacida- 
de de gasto. Sayd (2003) acrescenta a necessidade da existência de um padrão mais elevado de renda das famílias como precondição dos benefícios tributários, dados os limites de isenção para a tributação pelos impostos diretos. Pois, independentemente do gasto efetuado em saúde, apenas as famílias posicionadas em classes de rendimento não isentas de contribuição para o fisco conseguem deduzir esse gasto - o que não é peculiar ao caso brasileiro. Nos EUA, de acordo com Quadros, "o diferencial de despesa tributária referente a deduções associadas a planos de saúde é significativo entre classes. Os gastos tributários totais em saúde representaram em 1998 cerca de U\$ 111 bilhões, com benefícios médios de U\$ 71 por família na faixa de renda abaixo de U\$ 15000 e de U\$ 2357 por família para aqueles cuja renda é superior a U\$100 000" (QUADROS, 2000, p. 5). Trabalhos de âmbito europeu também corroboram essa característica (MOSSIALOS \& DIXON, 2002).

Cabe destacar que não foi encontrado, nos documentos examinados, um consenso a respeito da conceituação das deduções em saúde, do IRPF, como gasto ou beneficio tributário. De acordo com um documento elaborado pela assessoria técnica da Unafisco ${ }^{6}$ (UNAFISCO, 2003), o Ministério da Fazenda classificaria, de forma equivocada, as despesas com dependentes, educação e saúde do IRPF (despesas para um mínimo existencial) como beneficio tributário (renúncia fiscal), pois não representam um aumento da disponibilidade econômica do contribuinte, já que substituem despesas com serviços não garantidos, na prática, pelo Estado: "Não se pode renunciar a uma renda que não existe, pois o rendimento bruto não representa a capacidade contributiva do contribuinte. Esta só começa após a dedução dos gastos necessários a aquisição e manutenção da renda e do patrimônio, assim como do mínimo indispensável a uma existência digna para o contribuinte e sua família" (idem, p. 7).

Esse debate foi pouco visto fora do âmbito acadêmico, até os anos 2000. A partir de então, apareceu no Simpósio de Saúde Suplementar, realizado, em 2001, pela Câmara dos Deputados, parecendo refletir um interesse do poder Legislativo a respeito do aprofundamento da re6 Associação Nacional dos Auditores Fiscais da Receita
Federal do Brasil. gulamentação do setor de saúde suplementar, cujo debate perpassa a década de 1990, culminando na promulgação das leis n. 9656/98 e n. 9661/2000. Segundo o relatório desse simpósio, o financiamento público dos prêmios e dos serviços privados de saúde por meio da renúncia fiscal é polêmico, representando gastos sociais, já que são compartilhados pela sociedade. Por outro lado, essa renúncia pode constituir-se num elemento decisivo para a efetividade da ação tributária, na medida em que evidencia receitas de outra forma passíveis de sonegação no mercado de atenção direta à saúde.

O Fórum de Saúde Suplementar foi um evento promovido pelo Ministério da Saúde, em parceria com a Agência Nacional de Saúde Suplementar (ANS) e o Conselho Nacional de Saúde (CNS), entre junho e novembro de 2003. Reuniu representantes de diferentes setores da sociedade, envolvidos na relação entre mercado, Estado e "experts", para debater temas relacionados à assistência privada à saúde, com o objetivo de efetivar uma política nacional de saúde que englobe o setor suplementar. $\mathrm{O}$ financiamento do setor e a regulação de preços e reajustes estavam entre os temas discutidos. Foram produzidos dois relatórios finais e 41 documentos técnicos. As atas dos debates foram avaliadas. Dos documentos técnicos encomendados pela ANS, um abordou o problema, também, sob a óptica do maior peso dos gastos em saúde para as famílias dentro da faixa de isenção e da faixa de alíquota de $15 \%$, contribuindo para a iniqüidade do modelo de financiamento (VIEGAS, MAIA \& NORONHA 2003)

No Relatório Geral do Fórum de Saúde Suplementar, o debate apontou as seguintes questões: 1) que o envolvimento de recursos públicos no financiamento da chamada "saúde suplementar" era uma justificativa válida que autorizava uma maior abrangência da regulação do setor e 2) que também se justificava a discussão em torno da questão de se a aplicação dos recursos estaria devolvendo à sociedade bons serviços de saúde.

Propostas de eliminação explícita da renúncia fiscal com gastos privados em saúde aparecem no Relatório Final da $12^{\text {a }}$ Conferência Nacional de Saúde (CONSELHO NACIONAL DE SAÚDE, 2003). Em certa altura do relatório, ficou deliberado "suspender os subsídios oriundos da dedução de Imposto de Renda para gastos com planos 
e seguros de saúde, revertendo os valores correspondentes arrecadados para a constituição de um fundo nacional voltado para o financiamento de ações emergenciais em saúde e de atenção básica" (idem, p. 151, tópico n. 27). Isso poderia estar relacionado à inclusão do tema no Plano de Trabalho da Comissão de Saúde Suplementar do Conselho Nacional de Saúde, de 2004 (CONSELHO NACIONAL DE SAÚDE, 2004), no qual aparece, com destaque, a necessidade de aprofundamento de conhecimentos relativos às diferentes modalidades de apoio público à despesa privada em saúde. Um dos resultados da Comissão foi o relatório apresentado à plenária do $\mathrm{CNS}$, em outubro de 2005 (CONSELHO NACIONAL DE SAÚDE, 2005), incluído na pauta como "apreciação e votação da minuta de recomendação sobre aporte de recursos públicos em planos de saúde", baseada em documento prévio, aprovado na $154^{\mathrm{a}}$ Reunião Ordinária. A proposta previa a destinação dos recursos da renúncia fiscal ao Sistema Único de Saúde (SUS); resolução que foi polêmica. Um dos motivos assinalados era a existência virtual desses recursos, vinculados à efetiva possibilidade de abatimento das despesas no IRPF e no IRPJ. A resolução efetivamente aprovada em fevereiro de 2006 prescreve: "o CNS e ao Ministério da Saúde que proponham ao Ministério da Fazenda e à Receita Federal a criação de Grupo de Trabalho para discussão e avaliação dos encargos tributários relacionados à demanda e à oferta de serviços privados de saúde [...]"7 (CONSELHO NACIONAL DE SAÚDE, 2006, p. 41).

No caso do Congresso Nacional, consultamos o Sicon (Sistema de Informação do Senado), para um período legislativo que vai de 2003 a 2008, buscando a existência de projetos de lei que modificassem as regras atuais de deduções do Imposto de Renda. Constatou-se a ausência de qualquer iniciativa nessa matéria.

Finalmente, é importante examinar o documento do Ministério da Fazenda, "Política Econômica e Reformas Estruturais" (BRASIL, 2003a), que apresentou as prioridades da agenda econômica do Governo Federal e analisou os impactos soci-

\footnotetext{
$\overline{7 \text { Posteriormente a esse debate, } \mathrm{o} \text { assunto }}$ parece ter ficado congelado, sendo apenas citado entre outras medidas pendentes de resolução quanto ao financiamento da saúde em 11 de julho de 2007, na ata n. 175 do Conselho Nacional de Saúde.
}

ais da estrutura tributária. Nesse documento, foi sistematizado o principal objetivo da política econômica de diminuir a relação entre a dívida pública e o Produto Interno Bruto (PIB), por meio do aumento do superavit primário, sem ampliação da carga tributária. Em particular, o governo deixou claro sua intenção de atacar os tributos cumulativos, reduzir as alíquotas dos impostos indiretos e revisar os benefícios e renúncias fiscais de natureza regressiva - retomando a problemática dos subsídios destinados às famílias de maior poder aquisitivo, para fins dos seus gastos com serviços sociais. Em outro documento, a formulação da equipe do Ministério da Fazenda foi mais explícita: "a possibilidade de ampliação dos recursos destinados aos brasileiros mais pobres e de fornecer uma verdadeira rede de proteção social capaz de amparar a população mais vulnerável, depende, de forma decisiva, da realização de reformas estruturais que reduzam os privilégios concedidos pelo atual sistema - tanto por meio de gastos diretos quanto através de renúncias fiscais - a grupos de renda mais alta [...]. Na área da saúde cabem, ainda, reflexões sobre as renúncias tributárias em saúde (pessoa física e jurídica), auferidas por segmentos sociais de maior renda" (BRASIL, 2003b, p. 11).

\section{III.2. Entrevistas}

Uma questão importante a ser desvendada pela entrevista foi a importância do benefício tributário de pessoas físicas e jurídicas, em saúde, sobre o padrão atual de demanda e gasto. Quanto ao padrão de demanda, as respostas mais freqüentes não consideraram que a existência do beneficio tributário interferia na decisão dos indivíduos de pagarem planos de saúde ou procurarem atendimento ambulatorial. Ou seja, consideram a utilização privada como derivada de uma necessidade. Dois dos três representantes das famílias responderam dessa forma. Dos que consideraram importante, destacam-se a maioria dos representantes de prestadores, não havendo diferenças nas respostas em relação ao tipo de atenção privada (planos de saúde ou atendimento ambulatorial e hospitalar).

Quanto aos gastos, as famílias, em sua maioria, ressaltaram a falta de importância do benefício tributário frente aos gastos em saúde ${ }^{8}$. Os

8 "Gasta-se mais do que se pode abater" (resposta de
entidade de defesa dos consumidores aos pesquisadores). 
empresários assumiram uma posição semelhante, apesar de os trabalhadores, por sua vez, alegarem referir-se a esse benefício na negociação do plano de saúde empresarial.

Para o representante das famílias de renda mais alta, que respondia por uma entidade de advogados e trabalhava diretamente com questões tributárias, as empresas já fariam um planejamento tributário no qual nem sempre optariam por declarar todas as despesas dos empregados, em saúde, como gastos operacionais. Entre os prestadores, a maior parte também considerou o benefício como não importante. Um representante de planos de saúde afirmou ser "pequeno" o benefício, e um representante de clínicas considerou-o "inexistente", embora, para ele, a inexistência do beneficio tributário das pessoas físicas poderia acarretar em alguma redução em suas receitas. Por outro lado, os representantes do Estado afirmaram que a renúncia fiscal era, sim, importante para a manutenção do padrão de gastos, embora um deles admitisse que as pessoas jurídicas tenham margens maiores de compartilhamento de gastos com os próprios empregados.

Os impactos com a possível retirada do benefício, referidos pela maioria dos entrevistados, ajudam a evidenciar as diferenças de perspectiva quanto ao tema, por parte dos atores: por ordem de freqüência, eles foram:

a) Aumento da demanda ao SUS (sete em onze respostas), referindo-se especialmente às camadas sociais de renda mais baixa;

b) Mudanças na relação capital-trabalho (cinco em onze respostas). As questões referiram-se ao trade-off atualmente existente entre salário e benefícios, como os planos de saúde, em que o aumento do custo do último poderia acarretar na redução no primeiro. Além disso, poderia haver tendências ao aumento da participação do empregado no custeio do plano, posição expressada por essa categoria de atores. Também, a redução de benefícios, como a abrangência geográfica do plano e rede de prestadores de serviços. As respostas extremas, por parte de representantes de planos de saúde, referiram-se ao corte do plano. Por outro lado, o entrevistado especialista em questões tributárias aponta que as empresas teriam uma margem de manobra maior do que as pessoas físicas, podendo repassar parte do custo adicional advindo da redução do benefício fiscal aos preços, além da composição da própria declaração;

c) Impactos diversos sobre o orçamento e o gasto público em saúde (aumento ou redução);

d) Redução da demanda e receita dos prestadores privados (questão polêmica, com respostas divididas);

e) Aumento do item "saúde" no orçamento das pessoas físicas, com a limitação de gastos eletivos e desnecessários e o aumento dos encargos em saúde na sua renda, e também de sua carga tributária;

f) Redução da receita tributária dos prestadores de serviços de saúde. Um representante de planos de saúde refere-se à necessidade de estudos econométricos que estimem a resultante para as receitas públicas da redução das receitas dos prestadores vis-à-vis a eliminação do beneficio tributário em saúde das pessoas físicas e jurídicas;

g) Aumento da qualidade da atenção prestada ao SUS. Essa resposta foi dada pela maioria dos representantes do Estado, referindo-se ao retorno à clientela do SUS de camadas com maior tradição reinvidicatória.

A pesquisa revelou que o tema dos abatimentos em saúde não constava na agenda prévia de sua organização. Apenas as famílias já haviam abordado o problema, sendo que a de maior renda referiu-se a estudos realizados pela entidade acerca da questão tributária mais geral, não especificamente quanto ao objeto em questão. A entidade de defesa dos consumidores teria já realizado reuniões públicas em que o tema teria sido abordado, dentro da perspectiva de que o Estado não destinaria recursos suficientes ao sistema público e transferiria recursos para a atenção privada à saúde às pessoas físicas e jurídicas de diversas formas, inclusive indiretamente, por meio da renúncia fiscal. Dos prestadores, a minoria tem posicionamentos oficiais sobre a questão (planos de saúde e clínicas). Destaca-se a ausência das entidades dos médicos e dos empresários em debates prévios. Trabalhadores apontaram o debate sobre as vantagens dos abatimentos de pessoas jurídicas nas negociações coletivas.

No que se refere à posição oficial sobre o tema ou sobre temas correlatos, apenas três entidades posicionaram-se em alguma das categorias de nosso questionário: 
a) Representantes das famílias de maior renda: apresentam manifestações a favor da reforma tributária, desonerando a produção e aumentando o número de alíquotas do Imposto de Renda, de modo a tornar a política tributária mais equânime.

b) Representantes de planos de saúde: contrários à redução dos benefícios. Um deles mostrouse favorável ao aumento dos incentivos tributários, em geral, para a atenção privada à saúde.

c) Representante dos trabalhadores: resoluções do sindicato; favoráveis aos benefícios tributários.

Nenhum representante do Estado referiu-se a qualquer posição. Tampouco, empresários e prestadores de serviços de saúde (médicos e clínicas).

Se houvesse uma ameaça concreta de retirada do benefício, a maioria dos entrevistados (cinco em 14), especialmente os prestadores de atenção privada, provavelmente pensaria em organizar-se para combater a proposta. Os trabalhadores consideraram que as centrais sindicais e as confederações deveriam posicionar-se. A referência ao interesse do Ministério da Fazenda em conduzir essa mudança corroborou a pesquisa documental.

A análise global por categoria de atores, por sua vez, revelou o seguinte.

a) Estado. Admitem que benefícios fiscais têm algum papel no padrão atual de demanda e de gastos privados em saúde, com exceção de um entrevistado (em três), que não considera-os importantes para as pessoas físicas. Todos referem-se ao aumento da demanda em relação ao SUS, caso haja reduções dos benefícios. Não existem movimentos, como estudos ou posicionamentos concretos, embora esses atores tendam a considerar positivas as reformas dos benefícios.

b) Famílias. Não há interferência dos benefícios tributários sobre a demanda de atenção à saú$d e$, considerada uma necessidade. Para as famílias de maior renda, sim, no que se refere aos gastos, conquanto a retirada dos abatimentos em saúde, no IRPF, implicasse num maior gasto percentual em relação a seus rendimentos, e desde que a mudança dos serviços ofere- cidos acarretasse a utilização de um conjunto de serviços não essenciais. A entidade representativa das famílias de renda mais elevada é mais mobilizada pelas questões tributárias, defendendo, em geral, uma desoneração da produção e mais alíquotas de tributação, de acordo com a renda. Enquanto isso, os representantes das faixas de renda mais baixas, por beneficiarem-se pouco por esses abatimentos, não relatou qualquer interesse prévio na questão.

c) Trabalhadores. Admitem a importância dos abatimentos para os empresários e utilizam-no como argumento nas negociações por benefícios de saúde. Têm receio de aumentar a sua participação no custeio de planos de saúde, caso os abatimentos sejam reduzidos. Suas preocupações com o problema não se desdobram, ainda, em ações de mobilização no nível das confederações e das centrais sindicais.

d) Empresários. As decisões de fornecer benefício de atenção à saúde não tiveram relação com os abatimentos. Para os pequenos empresários, as receitas da empresa foram fatores mais relevantes, já que eles fizeram referência a optar por declarações simplificadas, consideradas mais vantajosas. Não referiram estudos ou debates prévios sobre o tema, mas, quanto a posicionamentos políticos em face de mudanças, as categorias empresariais do grande e do médio negócios revelaram uma posição contrária mais firme.

e) Prestadores de serviços.

e.1) Planos de saúde. Para as pessoas físicas, os benefícios fiscais não interfeririam na demanda e nos gastos em saúde, já para as pessoas jurídicas, sim. Uma entidade revelou-se mais mobilizada do que a outra, com posições oficiais sobre o tema. Ambas são contrárias à redução do beneficio.

e.2) Médicos e clínicas. Não houve consenso algum sobre a importância dos abatimentos fiscais a respeito da demanda de atenção à saúde. Sobre os gastos das pessoas físicas, os médicos não consideraram ser uma questão de qualquer importância. Entretanto, a eliminação do benefício acarretaria um peso maior do item "saúde" no orçamento das famílias. A maior parte nega o desenvolvimento de estudos ou a existência de um posicionamento oficial sobre o tema, e não saberia como a 
categoria manifestar-se-ia caso houvesse a eliminação do beneficio.

De um modo geral, destaca-se, ainda, que, para algumas categorias, o tema foi algo delicado, o que se manifestou na negação de participarem da entrevista, seja de maneira formal, seja de forma evasiva ${ }^{9}$. Essa reserva também foi encontrada numa entidade de médicos. A outra entidade dessa categoria, também com vasta experiência em tais fóruns de deliberação, embora reconhecesse os impactos negativos da eliminação do benefício fiscal sobre as famílias, considerou que mesmo pesquisas científicas não seriam convenientes na conjuntura atual, por permitirem um debate que possa favorecer os setores defensores da redução desses benefícios.

A seguir, apresentamos dois quadros, contendo as principais categorias identificadas no estudo documental e nas entrevistas, além de algumas diferenças encontradas nas opiniões dos sujeitos sociais.

QUADRO 3 - IMPORTÂNCIA DO BENEFÍCIO FISCAL EM SAÚDE PARA DIFERENTES SUJEITOS SOCIAIS

\begin{tabular}{|c|c|c|c|c|}
\hline \multirow[b]{2}{*}{ SUEITOS SOCIAIS } & \multicolumn{2}{|c|}{ DEMANDA PRIVADA EM SAÚDE } & \multicolumn{2}{|c|}{ GASTO PRNADO EM SAÚDE } \\
\hline & $\begin{array}{l}\text { Dependência de } \\
\text { isenção }\end{array}$ & $\begin{array}{l}\text { Importância da } \\
\text { isenção }\end{array}$ & $\begin{array}{c}\text { Dependência de } \\
\text { isenção }\end{array}$ & $\begin{array}{l}\text { Importância da } \\
\text { isenção }\end{array}$ \\
\hline $\begin{array}{l}\text { Famílias de menor } \\
\text { renda }\end{array}$ & Nẵo & Nẫo & Nẫo & $\begin{array}{c}\text { Nã̃o } \\
\text { (isento ou declaraçẫo } \\
\text { simplificada) }\end{array}$ \\
\hline $\begin{array}{l}\text { Famílias de maior } \\
\text { renda }\end{array}$ & Nẵo & Nẫo & Sim & Sim \\
\hline Estado & $\begin{array}{c}\text { Depende } \\
\text { (mais para pessoas } \\
\text { fisicas) }\end{array}$ & $\begin{array}{c}\text { Depende } \\
\text { (mais para } \\
\text { pessoas fisicas) }\end{array}$ & Sim & Sim \\
\hline $\begin{array}{l}\text { Planos e prestadores } \\
\text { de serviços de saúde }\end{array}$ & Depende & Depende & Sim & $\begin{array}{l}\operatorname{Sim} \\
\text { (garantia de receita) }\end{array}$ \\
\hline $\begin{array}{l}\text { Empregadores de } \\
\text { menor capital }\end{array}$ & $\begin{array}{c}\text { Nẫo } \\
\text { (para quem usa } \\
\text { declaraçốes } \\
\text { simplificadas) }\end{array}$ & $\begin{array}{c}\text { Não } \\
\text { (para quem usa } \\
\text { declaraçốes } \\
\text { simplificadas) }\end{array}$ & $\begin{array}{c}\text { Nẫo } \\
\text { (para quem usa } \\
\text { declaraçốes } \\
\text { simplificadas) }\end{array}$ & $\begin{array}{c}\text { Nẫo } \\
\text { (para quem usa } \\
\text { declaraçốes } \\
\text { simplificadas) }\end{array}$ \\
\hline $\begin{array}{l}\text { Empregadores de maior } \\
\text { capital }\end{array}$ & Nẫo & Nẫo & Nã̃o & $\begin{array}{c}\text { Nẫo } \\
\text { (planejamento } \\
\text { tributário) }\end{array}$ \\
\hline Empregados & Depende & Sim & Sim & $\begin{array}{c}\text { Sim } \\
\text { (item de negociaçẫo } \\
\text { com patrốes) }\end{array}$ \\
\hline
\end{tabular}

FONTE: Elaboração dos autores, a partir das entrevistas realizadas.

\footnotetext{
${ }^{9}$ No caso, duas entidades nacionais de importantes atores dos fóruns que deliberaram sobre as políticas de saúde; uma de prestadores e outra de trabalhadores.
} 
QUADRO 4 - CATEGORIAS EMERGENTES NAANÁLISE DE DISCURSO SOBRE BENEFÍCIOS FISCAIS EM SAÚDE DO IMPOSTO DE RENDA

\begin{tabular}{|c|c|}
\hline ANÁLISE DOCUMENTAL & ENTREVISTAS \\
\hline Inc entivo ao crescimento do setor privado & Decisẫo de utilizaçẫo independe da renúncia \\
\hline Beneficiam as famílias nẫo isentas & Gasta-se mais do que se abate \\
\hline $\begin{array}{l}\text { Substitui despesas com serviços nẫo garantidos } \\
\text { pelo Estado }\end{array}$ & Planejament o tributário favorece empresas maiores \\
\hline $\begin{array}{l}\text { Pode ser entendido como um gasto } \\
\text { compartilhado com toda a sociedade }\end{array}$ & $\begin{array}{l}\text { Argumento utilizado nas negociaçốes entre patrẫo e } \\
\text { empregados }\end{array}$ \\
\hline Auxilia controle da sonegaçẫo & $\begin{array}{l}\text { Estado considera positivo retorno ao SUS dos clientes } \\
\text { privados por serem clientela mais reirw idic atória }\end{array}$ \\
\hline \multicolumn{2}{|l|}{$\begin{array}{l}\text { Gastos privados em saúde sã̃o } \\
\text { proporcionalmente maiores para as famílias de } \\
\text { menor renda }\end{array}$} \\
\hline \multicolumn{2}{|l|}{$\begin{array}{l}\text { A isençẫo favorece a busca por serviço de saúde } \\
\text { privado }\end{array}$} \\
\hline $\begin{array}{l}\text { Extinçẫo desse abatimento como mecanismo de } \\
\text { promoçẫo da equidade }\end{array}$ & \\
\hline
\end{tabular}

FONTE: Elaboração dos autores.

\section{CONCLUSÕES}

A inclusão do tema dos abatimentos do IRPF e do IRPJ em gastos privados de saúde na agenda de estudos e na formulação de políticas esteve limitada ao âmbito acadêmico, até o final dos anos 1980, quando fez parte das mudanças mais gerais nas políticas tributárias e de saúde da Constituição de 1988. Foram efêmeras as mudanças, entretanto, pois, no início dos anos 1990, as regras de abatimento tornaram-se mais generosas para os contribuintes, nesse campo. A partir dos anos 2000 , foram identificados três importantes espaços de discussão sobre políticas de saúde, em que o tema foi abordado: o Simpósio sobre Planos de Saúde, promovido pela Câmara dos Deputados, em Brasília, no ano de 2001; a XIII Conferência Nacional de Saúde, realizada em 2003, e o Fórum de Saúde Suplementar, promovido pela ANS, em 2003. Um posição explicitamente favorável a mudanças de regras foram encontradas no Ministério da Fazenda, em alguns artigos acadêmicos da área de Saúde Coletiva e na tentativa, frustrada, do Conselho Nacional de Saúde de aprovar uma resolução nesse sentido, em 2006. Posição explicitamente contrária não foi encontrada. Quanto às organizações entrevistadas, embora temas de tributação e financiamento estejam presentes, com alguma freqüência, em sua agenda, a questão específica dos abatimentos em saúde de pessoas físicas e jurídicas somente foi percebida, de forma organizada, em duas entidades, das 14 entrevistadas - uma de defesa do consumidor e outra de planos de saúde; ambas freqüentadoras de fóruns nacionais de formulação de políticas, onde, de certa forma, esse debate ocorre.

Destaca-se a ausência de uma posição oficial do governo sobre o tema, a despeito da posição favorável do Ministério da Fazenda e de burocratas da área de saúde. Castiglioni (2003), em sua análise comparada da previdência social uruguaia e chilena nos anos 1980, destaca que, a despeito de uma orientação geral favorável em direção às políticas neoliberais, certo papel era reservado aos atores políticos internos ao governo, com poder de veto. A despeito, também, da distribuição do poder político, que impediu uma reforma ortodoxa no Uruguai; o que pode ter um papel no caso atual, pelo motivo de que não haveria, de forma mais clara, grupos de interesse disputando recursos em arenas de alocação de recursos públicos.

A importância do beneficio tributário, menos para as famílias e mais para as empresas, levantado por estudos econométricos internacionais, parece ter uma correspondência nas opiniões dos atores, em que o discurso familiar assinala a pouca interferência dos abatimentos, nas decisões de pagamentos de planos e de assistência ambulatorial, pareceu mais forte do que o contrário. A dificuldade de obtenção de informações das grandes empresas, infelizmente, aparece como um limitante dessas afirmações. O real papel dos abatimentos em suas decisões de gastos em saúde apenas foi indireta e tangencialmente abordado, 
por meio do importante depoimento do representante das famílias de renda mais alta (também especialista em questões tributárias) acerca do papel do planejamento tributário, relativizando a importância do benefício tributário Quadros (2000) também destaca que as empresas, no Brasil, utilizam-se freqüentemente do planejamento tributário, ou seja, de formas de declarar rendimentos, dentro da legislação, que reduzem impostos a pagar, a partir da estrutura tributária, de sua organização, localização etc.

Relações positivas entre gasto tributário, demanda e gastos em saúde das famílias e empresas estiveram mais presentes no discurso dos gestores públicos e privados, do sistema de saúde. Possivelmente, as famílias e empresas devem ter tomado essa posição por recearem certa redução de seus ganhos, caso os abatimentos fossem reduzidos ou eliminados. É interessante assinalar que os únicos entrevistados que se posicionaram de forma claramente favorável à eliminação dos benefícios fiscais foram dois dirigentes de órgãos públi$\cos$. Não entrando na pesquisa como grupo social afetado diretamente pela mudança, quanto aos seus rendimentos imediatos, entendeu-se que seus discursos representavam a explicitação de uma estratégia política, oriunda dos grupos de poder a que faziam parte, que disputam a direção do aparelho de Estado. A despeito de uma contradição interna com os interesses do grupo social a que pertencem (de rendas médias e altas e/ou trabalhadores formais), esses grupos apropriam-se de um discurso que persegue a eqüidade e a viabilização de um sistema público de qualidade, no qual consideram os benefícios fiscais com atenção privada à saúde como algo contraditório em relação à política de saúde. Argumentos semelhantes são encontrados no Ministério da Fazenda, que defende a eliminação da renúncia fiscal por motivos de focalização do gasto público,

O entendimento lukacsiano (LUKACS, 2004) sobre consciência, como o pensamento que os homens teriam caso compreendessem a sua situação e os interesses de classe decorrentes dela, revelou que, de modo geral, as diversas categorias sociais estudadas têm uma compreensão de seus interesses, embora poucos estejam mobilizados pelo tema. Aqueles que mais estão informados e mobilizados são exatamente os que participam de instâncias de formulação de políticas de saúde (o
Conselho Nacional de Saúde e a Câmara de Saúde Suplementar) em que o debate é limitado, não alcançando arenas onde a decisão de fato deve darse, como o Congresso Nacional. Faria (2003) ressalta que o papel das idéias e do conhecimento é importante na análise da formulação e implementação das políticas públicas, especialmente no que tange à formação da agenda, o que parece ser aqui o caso, já que, com exceção do Ministério da Fazenda, ela é impulsionada por atores bastante informados, originários das elites acadêmicas do país, sem correspondência (ou mesmo em contradição) com interesses materiais das suas próprias classes e frações de classe.

O papel dos abatimentos em saúde do imposto de renda de pessoa física e jurídica, quanto à questão mais geral da eqüidade no financiamento, parece ser um campo em que diversos objetivos convergem numa mesma medida. No entanto, tomado isoladamente, isso aumentaria a participação da saúde no orçamento familiar, sem que houvesse, automaticamente, uma alocação compensatória de mais recursos públicos para o setor. No caso das empresas, estimar-se-ia que as maiores sofressem menos impactos, devido ao seu planejamento tributário. As pequenas empregam outras formas de declaração de rendimentos, em que as despesas em saúde não são computadas. Porém, também não fornecem benefícios de assistência à saúde na mesma proporção que as maiores.

Um caminho frutífero para entender a estranha combinação de busca de eqüidade e de focalização apontada por atores diversos seria não tomar a chamada "renúncia fiscal" em saúde de forma isolada e pontual e, sim, em sua relação com a totalidade. A questão da justiça fiscal não é apenas uma agenda do setor da saúde; ela perpassa o sistema tributário brasileiro, como apontado pela entidade de advogados, pela pouca discriminação das faixas de tributação do IRPF ou pela isenção de tributação sobre ganhos financeiros. Além disso, uma necessária elevação dos gastos públicos em saúde de modo a desonerar famílias e empresas de gastos considerados, hoje, indispensáveis, não poderia basear-se apenas no corte desses subsídios, porque a sua magnitude - R $\$$ 3,5 bilhões, em 2005 - não garante um montante de recursos que suporte totalmente a atenção à saúde de forma universal. 
Maria de Fátima Siliansky de Andreazzi (siliansky@iesc.ufrj.br) é Doutora em Saúde Coletiva pela Universidade Estadual do Rio de Janeiro (UERJ) e Professora da Universidade Federal do Rio de Janeiro (UFRJ).

Bernardo Sicsú (bsicsu@iesc.ufrj.br) é Doutora em Saúde Coletiva pela Universidade Estadual do Rio de Janeiro (UERJ) e Professora da Universidade Federal do Rio de Janeiro (UFRJ).

Ivani Bursztyn é Doutora em Saúde Coletiva pela Fundação Oswaldo Cruz (Fiocruz).

Luiz Fernando Rangel Tura é Doutor em Medicina pela Unifersidade Federal do Rio de Janeiro (UFRJ) e Professor da mesma universidade.

Tássia Holguin (tassiagh@hotmail.com) é Mestre em Saúde Coletiva pelo Instituto de Estudos de Saúde Coletiva (IESC).

\section{REFERÊNCIAS BIBLIOGRÁFICAS}

ALEXANDER, J. C. 1998. Ação coletiva, cultura e sociedade civil : secularização, atualização, inversão, revisão e deslocamento do modelo clássico dos movimentos sociais. Revista Brasileira de Ciências Sociais, São Paulo, v. 13, n. 37, p. 5-31. Disponível em : http:// www.scielo.br/scielo.php?pid=S010269091998000200001\&script=sci_arttext. Acesso em : 18.nov.2009.

ALMEIDA, C. 1998. O mercado privado de serviços de saúde no Brasil : panorama atual e tendências da Assistência Médica Suplementar. Textos para Discussão, IPEA, Brasília, n. 599. Disponível em : http://www.cipedya.com/ web/FileDownload.aspx?IDFile=100943. Acesso em : 18.nov.2009.

ANDREAZZI, M. F. S. 1991. O seguro saúde privado no Brasil. Rio de Janeiro. Dissertação (Mestrado em Saúde Pública). Fundação Oswaldo Cruz.

BEGHIN, N. 2005. Gastos tributários sociais de ambito federal : uma proposta de dimensionamento. Brasília : UNB. Mimeografado.

BRAVO, M. I. S. 2001. Gestão Democrática na Saúde : o potencial dos Conselhos In : BRAVO, M. I. S. \& PEREIRA, P. A. P. (orgs.). Política Social e Democracia. São Paulo : Cortez, p. 43-65.

CASTIGLIONE, R. 2003, Pensões e soldados : o papel do poder, dos atores políticos com poder de veto e das ideologias sob o regime militar no Chile e no Uruguai. In : COELHO,V. S. P. (org.). A reforma da Previdência Social na América Latina. Rio de Janeiro : FGV, p. 65-100.
COAST, J.; MCDONALD, R. \& BAKER, R. 2004, R. Issues Arising from the use of Qualitative Methods in Health Economics. Journal of Health Services Research \& Policy, London, v. 9, n. 2, p. 171-176.

DAIN, S. 2000. Do Direito Social à Mercadoria. Rio de Janeiro. Tese (admissão de Professor Titular do Instituto de Medicina Social). Universidade Estadual do Rio de Janeiro.

DOWD, B; FELDMAN, R.; MACIEJEWSKI, M. \& PAULY, M. V. 2001. The Effect of Taxexempt Out-of-pocket Premiums on Health Plan Choice. National Tax Journal, v. 54, n. 4, p. 741-756.

FARIA, C. A. P. 2003. Idéias, Conhecimento e Políticas Públicas. Um inventário sucinto das principais vertentes analíticas recentes. Revista Brasileira de Ciências Sociais, São Paulo, v. 18, n. 51, p. 21-29. Disponível em : http:// www.scielo.br/pdf/rbcsoc/v18n51/15984.pdf. Acesso em : 17.dez.2009.

GRUBER, J. 2001. Taxes and Health Insurance. National Bureau on Economic Research, Cambridge, MA., Working Paper, n. 8657. Disponível em: http://www.nber.org/papers/ w8657.pdf?new_window=1. Acesso em : 17.dez.2009.

LUKACS, G. 2004. História e consciência de classe. Lisboa : M. Fontes.

MÉDICI, A. C. 1992. Incentivos Governamentais ao Setor Privado no Brasil. Revista de administração pública, Rio de Janeiro, v. 26, n. 2, abr.-jun., p. 79-115. 
MONTONE, J 2004, Evolução e desafios da regulação do setor de saúde suplementar. In : MONTONE, J. \& WERNECK, A. J. Regulação e Saúde, v. 3, t. 1. Rio de Janeiro : Agência Nacional de Saúde Suplementar.

MOSSIALOS, E. \& DIXON, A. 2002, Funding Health Care : an Introduction. In : MOSSIALOS, E; DIXON, A.; FIGUERAS, J. \& KUTZIN, J. (eds.). Funding Health Care : Options for Europe. London : Open University, p. 1-30.

OCKÉ-REIS, C. O. 1995. O setor privado em saúde no Brasil : os limites da autonomia. Rio de Janeiro. Dissertação (Mestrado em Medicina Social). Universidade do Estado do Rio de Janeiro.

PATTON, M. Q. 2002. Qualitative Research \& Evaluation Methods. Londres : Sage.

QUADROS, W. L. 2000. A renúncia fiscal ao segmento de assistência medica suplementar : a experiência brasileira em perspectiva comparada. Rio de Janeiro : Agência Nacional de Saúde Suplementar. Mimeografado.

SALVI, A. F. C.; DE PAUla, E. V. M. \& LOURES, M. M. G. 2003. Demonstrativo dos gastos governamentais indiretos de natureza tributária - conceituação. Estudos Tributári$o s$, Brasília, Secretaria da Receita Federal, n. 12.
SAYD, P. D. 2003. Renúncia Fiscal e Eqüidade na Distribuição de Recursos para a Saúde. Rio de Janeiro. Dissertação (Mestrado em Saúde Pública). Fundação Oswaldo Cruz.

SHEIL, S. J. \& HOGAN, P. 1999. Cost of TaxExempt Health Benefits in 1998. Health Affairs, v. 18, n. 2, p. 176-181.

SOBO, E. J. 2009. Culture and Meaning in Health Services Research. Walnut Creek, California : Left Coast.

UGÁ, M. A. D. \& SANTOS, I. S. 2005. Uma análise da eqüidade do financiamento do sistema de saúde brasileiro. Relatório de Pesquisa. Projeto Economia da Saúde. Rio de Janeiro : Fundação Oswaldo Cruz. Relatório de Pesquisa, Cooperação Técnica Brasil-Reino Unido ENSP-FIOCRUZ. Disponível em : http:// www.opas.org.br/observatorio/arquivos/ Destaque99.pdf. Acesso em : 17.dez.2009.

VIEGAS, M. V.; MAIA, A. C. \& NORONHA, K. V. M. S. 2003. Financiamento do Setor de Saúde Suplementar no Brasil : uma investigação empírica a partir dos dados da PNAD/98. Rio de Janeiro : Agência Nacional de Saúde Suplementar.

WERNECK VIANNA, M. L. 1998. A americanização (perversa) da Seguridade Social no Brasil. Rio de Janeiro : IUPERJ.

\section{OUTRAS FONTES}

BRASIL. MINISTÉRIO DA FAZENDA. 2003a. Política econômica e reformas estruturais. Brasília : Ministério da Fazenda. Disponível em : http://www.fazenda.gov.br/portugues/ releases/2003/r030410.doc. Acesso em : 17.dez. 2009

.2003b. Gasto Social do governo central : 2001 e 2002. Econômica, Rio de Janeiro, v. 5, n.1, p. 9-69. Disponível em : http:// www.fazenda.gov.br/portugues/documentos/ 2003 Gasto\%20Social\%20do\%20Governo \%20Central\%202001-2002.pdf. Acesso em : 17.dez.2009.
CONSELHO NACIONAL DE SAÚDE. 2003.

$12^{a}$ Conferência Nacional de Saúde. Relatório Final. Brasília : Ministério da Saúde. Disponível em : http://conselho.saude.gov.br/biblioteca/Relatorios/relatorio_12.pdf. Acesso em : 16.dez.2009.

COMISSÃO PERMANENTE DE SAÚDE SUPLEMENTAR. 2004. Plano de Trabalho. Brasília : Ministério da Saúde.

2005. Ata da centésima qüinquagésima nona reunião ordinária do Conselho Nacional de Saúde. Brasília : Ministério da Saúde. Dis- 
ponível em : http://www.conselho.saude. gov.br/atas/2005/Ata159.doc. Acesso em : 16.dez.2009.

2006. Ata da centésima sextagésima primeira reunião ordinária do Conselho Nacional de Saúde. Brasília : Ministério da Saúde. Disponível em : http://www.conselho.saude. gov.br/atas/2006/Ata162.doc. Acesso em : 16.dez.2009.
IBGE. 2008. Saúde: uma perspectiva macroeconômica: 2002 - 2005. Rio de Janeiro : IBGE.

UNAFISCO Sindical. 2003. O Imposto de Renda na Reforma Tributária. Fundamentos da Campanha Imposto de Renda com Justiça. Brasília, UNAFISCO. Mimeografado. 
THE AGENDA FOR TAX REFORM ON HEALTH BENEFITS - FIRMS AND FAMILIES BETWEEN THE GENERAL AND THE PARTICULAR

\section{Maria F. S. Andreazzi, Bernardo Sicsú, Ivani Bursztyn, Luiz F. R. Tura and Tássia Holguin}

This article seeks to analyze the relationship between fiscal tax benefits for health expenditures and private health care demand. We seek to identify conflicts and agreements over the issue, particularly regarding proposals for change in the regulatory framework. In order to accomplish this we analyze documents and carry out semi-structured interviews with representatives of pertinent national organizations of social subjects. We are able to verify that the debate has reached important arenas for the definition of health policies, but proposals for change have not become viable. Our interviews suggest a convergence with international econometric studies on the non-elasticity of demand for family health care, while this is less true regarding firms. This also suggests that the issue should be placed within a broader context with regard to equity in financing, not focusing in an isolated manner on the specific matter of the elimination of this subsidy which would increase the onus of health care costs within the family budget and family tax burdens without automatically generating a compensatory allocation of public resources for the sector.

KEYWORDS: tax expenditures; private health expenditures; public-private relations in health; political economy of health; health policies in Brazil. 
L'AGENDA DE LA RÉFORME DES AVANTAGES FISCAUX EN SANTÉ DES FAMILLES ET DES ENTREPRISES : ENTRE LE PARTICULIER ET LE GÉNÉRAL

Maria de Fátima Siliansky de Andreazzi, Bernardo Sicsú, Ivani Bursztyn, Luiz Fernando Rangel et Tura Tássia Holguin

Cet article analyse le lien entre l'avantage fiscal pour la santé de l'impôt sur le revenu (individus et entreprises) avec la demande privée de la santé. Nous cherchons à identifier les conflits et les accords sur le sujet, en particulier, les propositions de modifications du cadre réglementaire. Pour ce faire, nous avons mené des études documentaires et des entretiens semi-structurés avec les représentants des organisations nationales des sujets sociaux se rapportant au sujet. Nous avons observé que le débat a atteint des arènes importantes de l'élaboration des politiques en matière de santé, mais les propositions de changement n'ont pas réussi à être réalisables. Les entrevues suggèrent une convergence vers les études internationales économétriques sur l'inélasticité de la demande en matière de santé beaucoup plus pour les familles, et moins pour les entreprises. Ceci suggère que la question devrait plutôt être incluse dans un contexte plus large par rapport à l'équité dans le financement, au lieu d'être reliée séparément au point spécifique de l'élimination de cette subvention ce qui pourrait accroître la participation de la santé dans le budget familial mais également le fardeau fiscal des familles, sans y avoir automatiquement une allocation compensatoire de davantage de ressources pour le secteur public.

MOTS-CLÉS : dépenses fiscales ; dépenses privées de santé ; relation public-privé en santé ; économie politique de la santé ; politique de santé au Brésil. 